Article

\title{
Experimental Investigation on the Heat Flux Distribution and Pollutant Emissions of Slot LPG/Air Premixed Impinging Flame Array
}

\author{
Haisheng Zhen (D, Baodong Du, Xiaoyu Liu, Zihao Liu * and Zhilong Wei * \\ The Mechanical and Electrical Engineering College, Hainan University, Haikou 570228, China; \\ ban18@126.com (H.Z.); baodong_du@sina.cn (B.D.); lxyu6@126.com (X.L.) \\ * Correspondence: liuzihao@hainanu.edu.cn (Z.L.); zhilongwei@hainanu.edu.cn (Z.W.); \\ Tel./Fax: +86-898-66267576 (Z.L.); +86-898-66267576 (Z.W.)
}

Citation: Zhen, H.; Du, B.; Liu, X.; Liu, Z.; Wei, Z. Experimental Investigation on the Heat Flux Distribution and Pollutant Emissions of Slot LPG/Air Premixed Impinging Flame Array. Energies 2021, 14, 6255. https://doi.org/10.3390/en14196255

Academic Editor: Muhammad Aziz

Received: 30 August 2021

Accepted: 29 September 2021

Published: 1 October 2021

Publisher's Note: MDPI stays neutral with regard to jurisdictional claims in published maps and institutional affiliations.

Copyright: (C) 2021 by the authors. Licensee MDPI, Basel, Switzerland. This article is an open access article distributed under the terms and conditions of the Creative Commons Attribution (CC BY) license (https:// creativecommons.org/licenses/by/ $4.0 /)$.
Abstract: Experiments were carried out to investigate the heat transfer and pollutants emission characteristics of a slot LPG premixed flame array impinging normally onto a flat plate. The effects of jet-to-jet spacing $(S / d e)$, nozzle-to-plate distance $(H / d e)$, and jet Reynolds number $(R e)$ on the heat flux and emission index of $\mathrm{CO}, \mathrm{CO}_{2}$, and $\mathrm{NO}_{\mathrm{x}} / \mathrm{NO}_{2}$ were examined. In addition, the thermal and emission characteristics between slot jets and circular jets were compared under identical experimental conditions. The results show that the more uniform heat flux distribution and higher total heat flux can be obtained at moderate jet-to-jet spacing, large jet-to-plate distance, and higher Reynolds number. EICO emissions can be influenced by the combined effects of jet-to-jet spacing, jet-to-plate distance, and higher Reynolds number. For the sake of the better combustion efficiency and lower EICO emission, the moderate jet-to-jet spacing $(S / d e=2.5)$, larger jet-to-plate distance $(H / d e=4)$, and relatively higher Reynolds number $(R e=1500)$ are preferred for the slot jet flame array. Furthermore, it is found that there exists a trade-off between the EICO and EINOx of the slot LPG flame array. Compared with multiple circular flame jets, multiple slot flames jets have the higher area-averaged heat flux due to the larger heating area and more uniform heat flux distribution, while the higher EICO emission and lower EINO ${ }_{x}$ emission are due to the greater jet interaction suppressing the air entrainment. Thus, it is known that the slot flame array has a better heating performance but relatively higher pollutant emissions than the circular flame array.

Keywords: LPG; slot impinging flame array; heat flux; pollutant emission

\section{Introduction}

Direct flame impingement heating is encountered in many applications demanding high heating fluxes, such as annealing of metal sheets, solution heat treatment of aluminum castings, domestic cooking, etc. Multiple flames are normally motivated by these applications, as flame jets arranged in an array provides the uniform heating of a large surface area and thus avoids local hot spots. This attractive attribute of multiple impinging flames has stimulated various empirical and numerical studies on their flow and heat transfer characteristics [1-5].

Dong et al. [1,2] studied the combined effect of Reynolds number, equivalence ratio, and jet-to-plate distance on the heat transfer of an array of two circular flame jets and triple in-line circular flame jets. A significant interference was observed between the flame jets, especially when both the jet-to-plate distance and the jet-to-jet spacing are small. The heat transfer in the interacting zone was reduced by the between-jet interference. The maximum heat transfer occurred when both the jet-to-plate distance and the jet-to-jet spacing were set at a moderate value. Kwok et al. [6] investigated the flame shapes and heat transfer characteristics of an array of three laminar butane/air slot flame jets that impinge upwards normally onto a flat plate under different jet-to-plate distances and jet-to-jet spacing. Their 
results revealed the necessity of matching the flame length with the jet-to-plate distance in order to obtain the optimum heat transfer performance. In addition, it was found that the slot flame jet yields more uniform and higher heat fluxes than the circular flame jet. Chander and Ray [7] performed the experiments to study the heat transfer characteristics of three interacting methane/air flame jets that were arranged in a triangular configuration and impinged on a flat surface. They also suggested that the heat transfer is related to the inter-jet spacing and separation distance. The available information about multiple impinging flame jets was related to the study of radial jet reattachment fames and the multijets used in the rapid heating furnace. Mohr et al. [8] investigated the thermal performance of radial jet reattachment flames with two flame jets, while the heat transfer behaviors of radial jet reattachment flames with three flame jets was investigated by Wu et al. [9]. Although numerous studies have been conducted to investigate the heat transfer features of a single jet flame, the research on the heat transfer characteristics of an imping flame array is quite limited. Thus, more efforts should be made to analyze the heat transfer process of a jet flame array.

Additionally, the previous studies with premixed impinging flames have primarily focused on the understanding of heat transfer with limited information available about pollutant formation, both for single and multiple jets. Exhaust gas analysis of the combustion products becomes very important regarding the more stringent norms set by the pollution control agencies [10]. Flame quenching, due to the interaction between the flame and impingement surface, will adversely affect the chemical kinetics and pollutant emission [11]. Mishra [12] investigated the flame structure and emissions of a LPG premixed flame impinging on a circular flat plate and found that the $\mathrm{CO}$ level increases with separation distance under all Reynolds numbers, the $\mathrm{NO}$ level decreases with an increase in equivalence ratio and Reynolds number, and the $\mathrm{CO}_{2}$ level increases with the equivalence ratio for all Reynolds numbers. Mohr et al. [13] reported that the RJRC jet produces a very low production of both $\mathrm{CO}$ and $\mathrm{NO}_{\mathrm{x}}$ and also very little soot and suggested that this type of burner is suitable for the flame impingement heating to control the pollutant emissions. Li et al. [14] investigated the effect of plate temperature on the heat transfer and emissions of a premixed LPG/air circular impinging flame jet. They advised that the heat transfer, $\mathrm{CO}$, and $\mathrm{NO}_{\mathrm{x}}$ emissions are significantly affected by the impingement plate temperature. Wei et al. $[15,16]$ investigated the pollutant formations of the impinging flame and found that the $\mathrm{CO}$ and NOx emission can be improved by the flame-quenching process. Furthermore, $\mathrm{CO}_{2}$ is considered as a major contributor to global warming [17-19], and its emission during the flame impingement also needs to be studied with the increasingly stringent regulations. Overall, it is known that quite a few studies have been conducted to study the pollutant emissions of an imping flame, especially for the multiple impinging flame jets. Thus, more studies need to be carried out to investigate the pollutant emissions of multiple impinging flame jets considering its broad applications in the domestic and industrial fields.

Since LPG has been widely used as the fuel for the flame impingement heating, it is adopted in this study to generate the impinging flame array in order to obtain the more comprehensive understanding on this fuel. The objective of this study is to investigate the heat transfer and exhaust emission characteristics of an array of triple in-line slot LPG premixed flame jets impinging on a flat plate, which can improve the understanding of the impinging heating process of a flame array and the combustion characteristics of LPG. Furthermore, this paper will analyze the effects of Reynolds number, jet-to-jet spacing, and jet-to-plate distance on the heat transfer and exhaust gas emissions, including $\mathrm{CO}$, $\mathrm{CO}_{2}$, and $\mathrm{NO}_{\mathrm{x}} / \mathrm{NO}_{2}$. In addition, the heat transfer and emission characteristics of the slot jet and circular jet flames will be compared and discussed in order to obtain the more comprehensive understanding of the slot flame pattern. 


\section{Experimental Setup}

The flame impingement system for the current study is schematically shown in Figure 1. It is composed of a flame holder, impingement plate, and reactants feeding system. The flame array consists of three identical slot nozzles, and each nozzle has a dimension of $13.4 \mathrm{~mm} \times 4.3 \mathrm{~mm}$ such that this flame holder has an equal effective diameter of $d e=12 \mathrm{~mm}$. Three nozzles are aligned in a line, and each nozzle has a length of $300 \mathrm{~mm}$ to ensure fully developed flow at the nozzle exit. The flame holder was fixed on a 3D positioner so as to move the flame more accurately. The coordinate used for the impingement system is also given in Figure 1. For the better comparison, normalized operational parameters were used, including jet Reynolds number $(R e)$, equivalence ratio $(\phi)$, jet-to-jet spacing $(S / d e)$, and nozzle-to-plate distance $(H / d e)$, where $S$ denotes the spacing between the centroids of two neighboring nozzles and $H$ is the distance from nozzle exit to the plate surface.

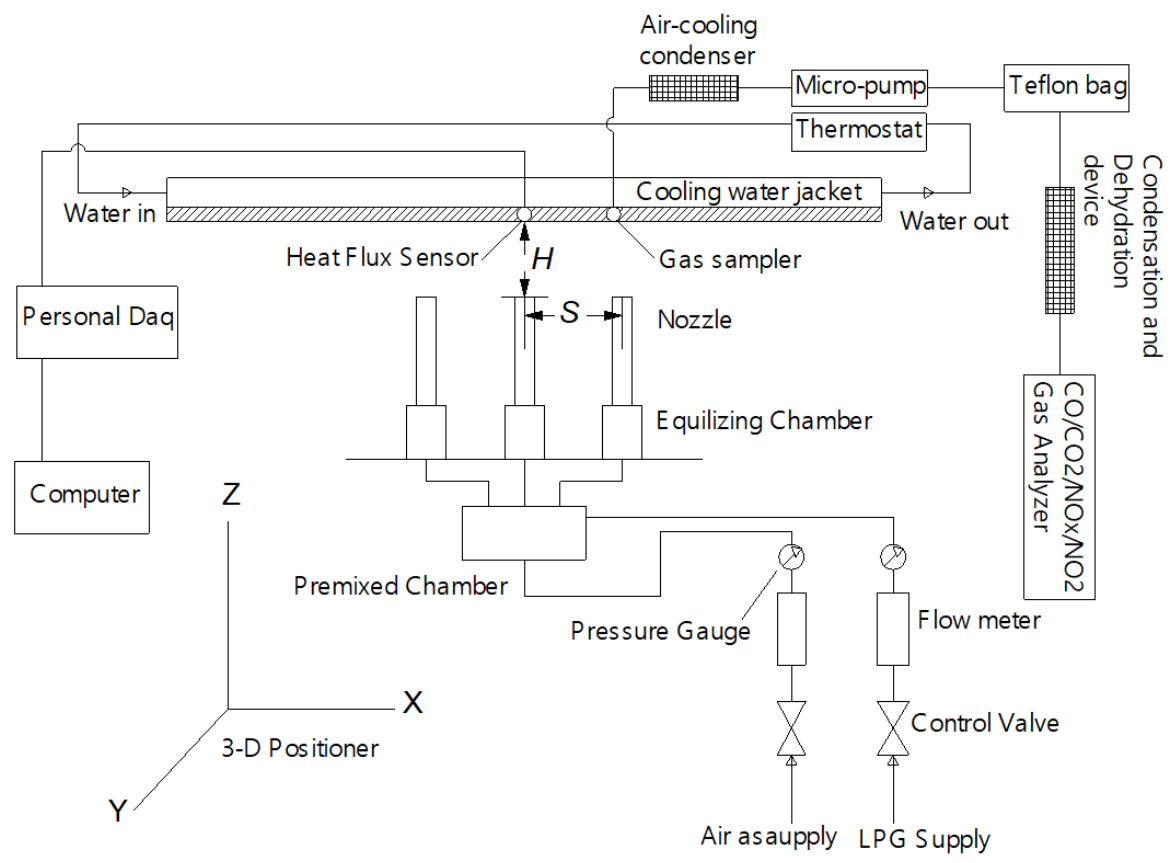

Figure 1. Experimental setup.

Liquefied petroleum gas (LPG) composed of 70\% butane and 30\% propane by volume is used as the fuel, and compressed air is adopted as the oxidant. The mixing chamber is filled with small stainless steel beads to guarantee the homogeneous mixture. The equivalence ratio of 1 is adopted in this work in order to guarantee the stable laminar flames. To prevent the misdistribution of the mixture flow among three nozzles and to reduce the non-uniform flow caused by the interaction between the jets, the mixture goes into three calibrated flow meters. This means that the flow rate in each of three jets can be controlled and measured individually in order to ensure the accurate operation of all jet flows under different conditions.

The impingement plate is a water-cooled copper plate that has a surface area of $500 \times 500 \mathrm{~mm}^{2}$ and a thickness of $8 \mathrm{~mm}$. The cooling water is controlled at a constant temperature of $38{ }^{\circ} \mathrm{C}$ by a thermostat to avoid the condensation of water vapor on the impingement plate. A heat flux transducer with an effective sensing area of $2 \times 2 \mathrm{~mm}^{2}$ is inserted at the center of the plate to measure the local heat flux of impinging flames. By traversing the 3D positioner horizontally, the local heat flux distribution within the $\mathrm{x}-\mathrm{y}$ plane can be measured. The positioner can also move and fix the burner at different $\mathrm{z}$ locations to achieve the desired nozzle-to-plate distance. A data acquisition system is used 
to record the heat flux data. The reported data are the averaged ones obtained consecutively in two minutes at a rate of 10 samples per second.

Exhaust gas emitted from the impinging flame is sampled through a small $1 \mathrm{~mm}$ diameter hole that is drilled through the impingement plate [14]. For pollutant emission measurement, this sampling hole is off the stagnation point with a certain a radial distance. Sufficient time can be guaranteed to obtain the steady state of gaseous species. The concentrations of gaseous species including $\mathrm{CO}, \mathrm{CO}_{2}, \mathrm{O}_{2}$, and $\mathrm{NO}_{\mathrm{x}} / \mathrm{NO}_{2}$ are extracted from the flame exhaust and then are air-cooled to about $30{ }^{\circ} \mathrm{C}$ to freeze the chemical reactions. The sampled gases are subsequently sent to a multi-gas analyzer system, which has the electrochemical cell for $\mathrm{O}_{2}$ measurement, the chemiluminescence CLA for $\mathrm{NO} / \mathrm{NO}_{2} / \mathrm{NO}_{x}$ measurement, and a non-dispersive infrared NDIR for $\mathrm{CO} / \mathrm{CO}_{2}$ measurement. Water vapor is condensed and removed from the samples before entering the analyzers. Zero and span calibrations are performed before and after each measurement to ensure the accuracy of data measurement.

The emission indices are calculated based on an atom balance, the measured $\mathrm{CO}_{2}$, and pollutant species concentrations. To guarantee experimental repeatability, each measurement is carried out for three times, and the averaged data are reported and employed to conduct an error analysis. The uncertain analysis is performed by the method suggested by Kline and McClintock [20]. With a 95\% confidence level, the uncertainties are $9 \%$ in flame temperature, $9.4 \%$ in $\mathrm{CO}$ concentration, $10.0 \%$ in $\mathrm{NO}_{\mathrm{x}}$ concentration, and $8.4 \%$ in $\mathrm{CO}_{2}$ concentration.

\section{Results and Discussions}

\subsection{Heat Flux Distributions}

Figure 2 illustrates the heat flux distribution of the LPG flame array along the $x$ coordinate at different conditions. As shown in Figure 2a, for $H / d e=2$ and $S / d e=1$, the heat flux increases to a peak value in a radial position slightly away from the centerline, indicating the occurrence of a cool core of the center jet flame. In addition, thanks to the quite strong between-jet interference at $S / d e=1$, the cool central core of the center and side jet can be affected and destroyed respectively by the outwardly flowing burned gases of the central jet flame. This results in the relatively high heat flux in the axis of the center flame and the continuously decreased heat flux with the increased $r / d e$, as shown in Figure 2a. As the $S$ / de ratio increases to 2.5 , due to the effectively weakened between-jet interaction, the heat flux profile exhibits three peaks, with the maximum heat flux occurring slightly to the outer side of the centerline of the side jet and then decreasing monotonically further outside. However, it is noted that the jet interaction can weaken the impingement heat transfer between the center jet and side jet due to the worse field synergy there, which contributes to the decreased heat flux in the jet-interaction zone. For the maximum value of $S / d e$ of 4 , there are three peaks, occurring at the centers of the central jet and side jets, respectively. Furthermore, the interaction between the three jets is very small, and they behave almost independently as individual single jets. Hence, three peaks of local heat flux are found at the centerline of each jet, and the heat fluxes in the between-jet regions are low.

As shown in Figure $2 b$, it is seen that as $H / d e$ was increased to 4 , the heat flux distributions are changed considerably and associated with different $S /$ de ratios. For $S / d e=1$, the heat flux increased to a peak value, which was near the center of the side jet, and then, it decreased monotonically outwards along the plate. In addition, although the jet interaction is still quite strong due to the small $S / d e$, the larger $H / d e$ can weaken this effect on the heat flux at the axis of the center flame by the comparatively moderate impingement than that at $H / d e=2$. Hence, the cool core plays a dominant role in the heat flux at the axis of the center flame, which gives rise to the quite low heat flux at the axis at $S / d e=2.5$ and $H / d e=4$, as shown in Figure $2 b$. For $S / d e$ ratios of 2.5 and 4 , the heat fluxes show the relatively flatter distributions in the radial direction. Additionally, it is noted that when the jet-to-plate distance is increased to 4 at a constant $S / d e$ ratio, a lower value of heat flux can be obtained in comparison with that at $H / d e=2$. This is caused by the larger 
distance between the reaction zone of the flame and the impingement plate causing a decay of the thermal performance of the flame-plate system due to the entrainment of excessive ambient air. In addition, the increased jet-to-plate distance also contributes to a smaller contact area between the flame and plate than that at the smaller $H$ /de ratio. Furthermore, it is evident that for the constant $S$ /de ratio and $H /$ de ratio, the heat flux can be increased evidently with an increased Reynolds number due to the stronger convection as shown in Figure 2a,b.
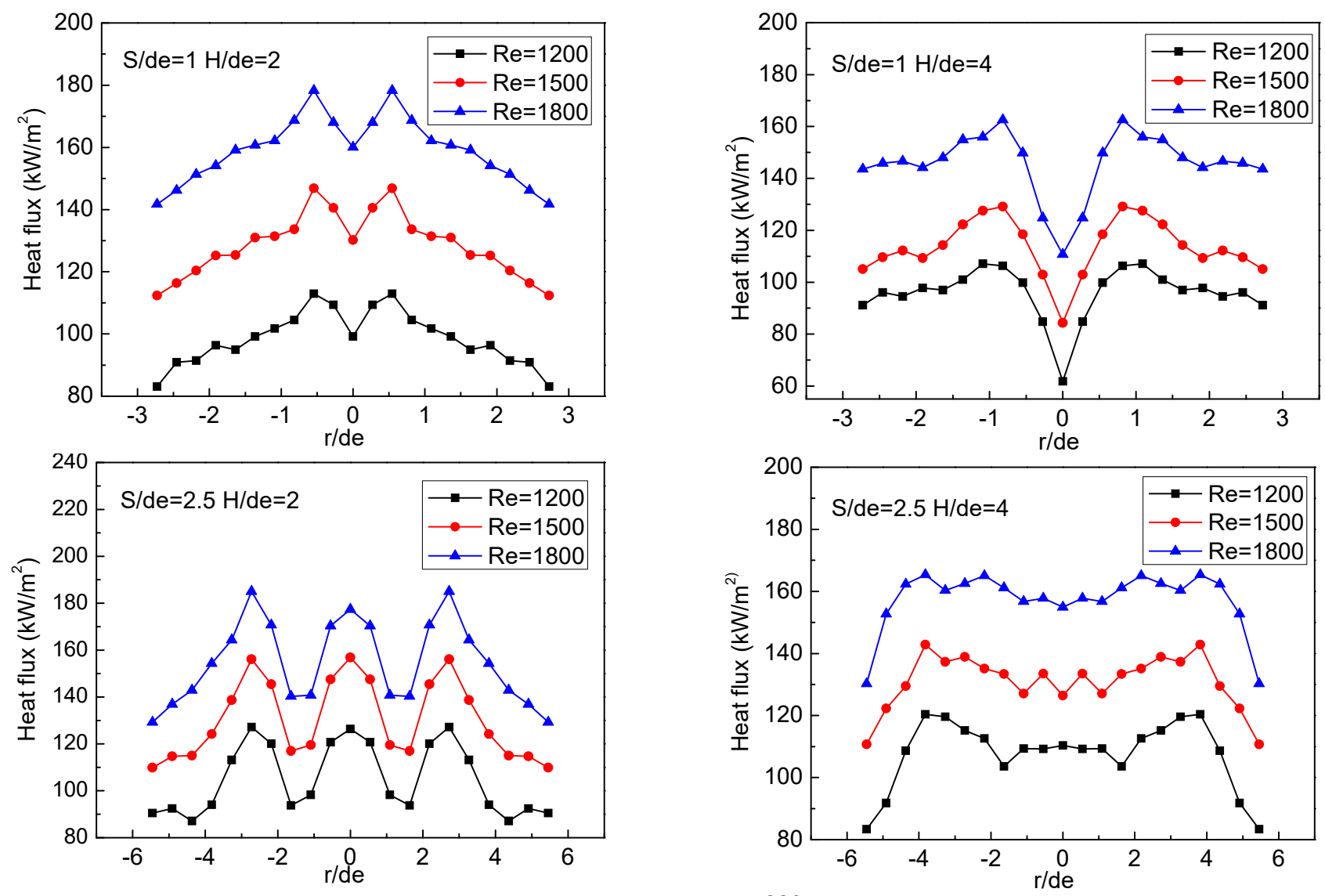

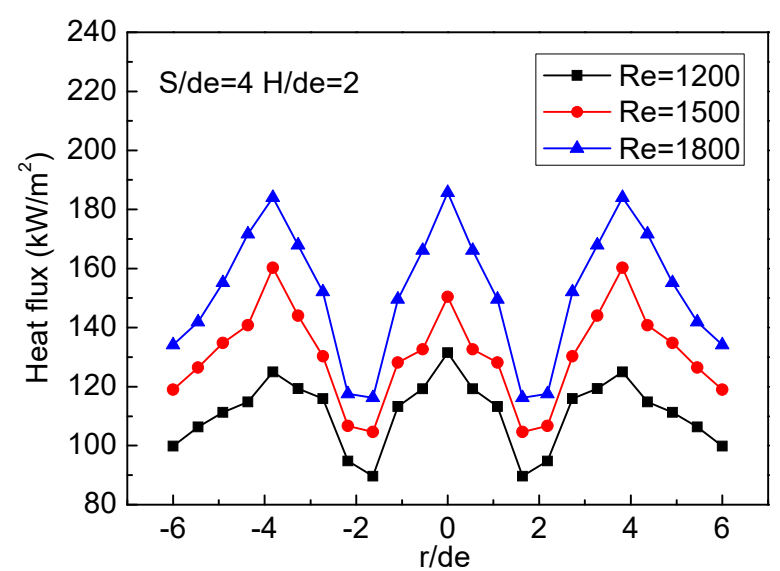

(a)

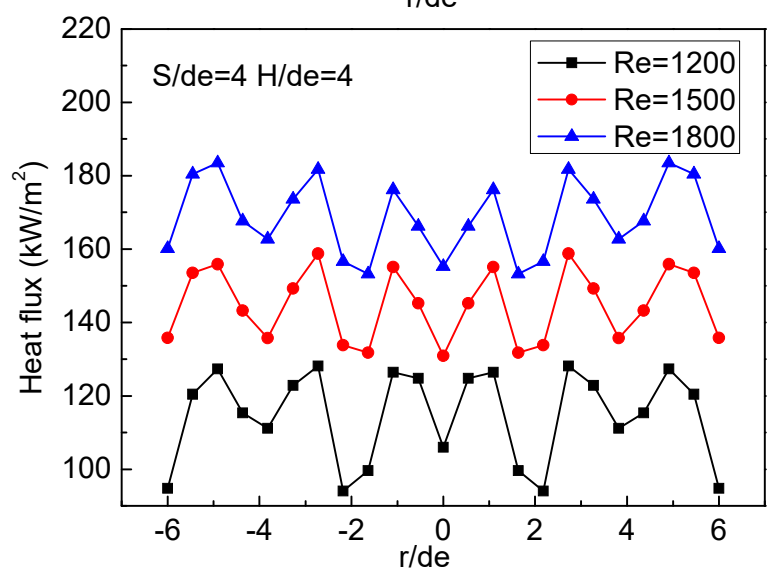

(b)

Figure 2. (a) Heat flux distribution along the slot width direction of an LPG premixed flame array at $H / d e=2$; (b) Heat flux distribution along the slot width direction of an LPG premixed flame array at $H / d e=4$. 


\subsection{Average and Total Heat Flux}

For most applications, average heat flux is an important parameter for evaluating the thermal performance of a heating system. To better understand the thermal performance of the impinging premixed flames in the present study, the averaged heat fluxes are illustrated in Figure 3.

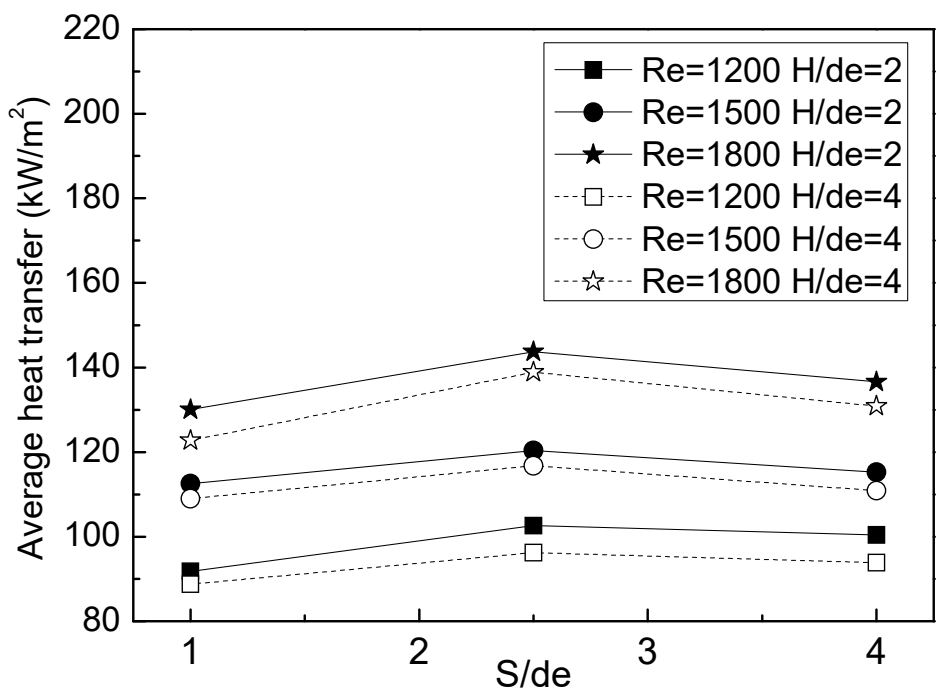

Figure 3. Area-averaged heat flux distribution of an LPG premixed flame array.

In all the cases, the average heat flux increases with the increased Reynolds number but decreases with the increasing jet-to-plate distance. As the Reynolds number increases, the higher flow velocity of the fuel/air mixture promotes higher convective heat transfer and then higher average heat flux. Moreover, a higher Reynolds number with a fixed equivalence ratio increases the heights of the inner and outer flame. The longer flame region extends to a further radial position along the impingement plate and results in the higher gas temperature within the boundary layer. At a high $\mathrm{H} / \mathrm{de}$ ratio, the combustion in the free jet region before impingement develops relatively more complete. Therefore, the flame in the wall jet region decreases in length and thus occupies less area on the target plate, which results in a lower gas temperature in the boundary layer and higher heat loss. This leads to a monotonic decrease in the average heat flux as shown in Figure 3. Saha et al. [21] investigated the variation of average heat flux with $H / d$ ratio for a rich methane flame. Their results showed that the average heat flux first increases with the $H / d e$ ratio to reach a peak value at $H / d e=2$ and then decreases with further increased $H / d e$, which has similar results to our study.

For all the Reynolds numbers and $H / d e$ ratios, the average heat flux increases to a maximum value at $S / d e=2.5$ and then decreases on both sides, as shown in Figure 3 . This means that the strong jet interference at the smallest $S /$ de ratio weakens the impingement heat transfer effectively because the more intensive flow of burned gases along the negative $\mathrm{z}$ direction is induced by the outward flow clash between the center flame and side flame. In addition, modest interference is beneficial for the heat transfer in the jet interaction region, which causes an enhancement of the heat flux as shown in Figure 3. At the largest $S / d e$, the jet interference can be negligible, which results in a low average heat flux. Similar results are found by Kwok et al. [6] and Dong et al. [22].

To improve the understanding of the thermal performance of the flames under different considerations, the total heat flux is also calculated at various conditions, as shown in Figure 4. The area-weighted method used in [23] is adopted in this work in order to calculate the total heat flux based on the measured local heat flux. At $R e=1200$, the total heat flux increases slightly with the increase in the jet-to-jet spacing and jet-to-plate distance. At $R e=1500$, the maximum heat flux occurs at a $S /$ de ratio of 2.5 rather than $S /$ de ratios of 
1 and 4. Furthermore, it is noted that compared with that at an $H / d e$ ratio of 2, there exists the higher heat flux at an $H$ /de ratio of 4 , as shown in Figure 4 . At $R e=1800$, the heat flux slightly increases with an increase in the jet-to-jet spacing but decreases with the jet-to-plate distance. It is known that the jet interference increases with the decrease in the $S / d e$ and $H / d e$ ratio. At $R e=1200$, the flame has a comparatively lower flame height than that at a high Reynolds number, which can weaken the negative effects of jet inference on the impingement heat transfer in the jet interaction zone. Thus, the flame array has the higher total heat flux at $H / d e=2$ owing to the larger heating region. By contrast, as Re is further increased, the increased flame height can result in the more intensive flow impingement, which can further promote the negative effects of jet inference on the impingement heat transfer in the jet interaction zone at $H / d e=2$, resulting in the worse convective heat transfer. With the increased $H / d e$, the flow impingement can be weakened considerably due to the increased jet-to-plate distance, which then weakens the jet inference effectively and gives rise to the better convective heat transfer in the jet interaction region. Thus, the total heat fluxes at $R e=1500$ and 1800 are enhanced when $H / d e$ is increased from 2 to 4 , as shown in Figure 4 .

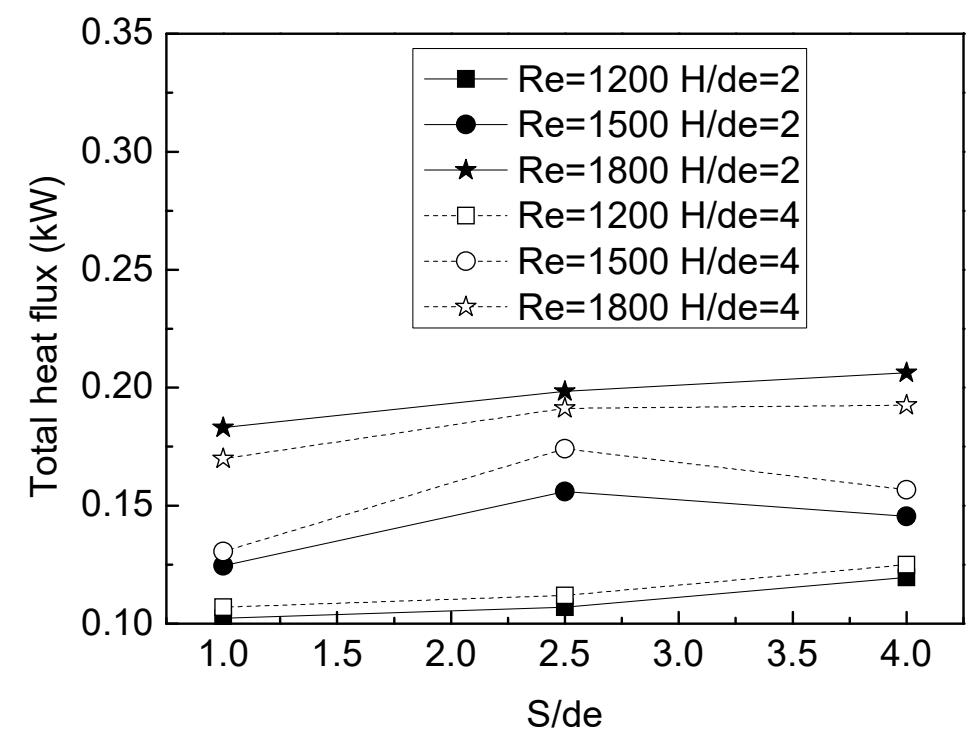

Figure 4. Total heat flux variations of LPG premixed flame array.

\subsection{Exhaust Emissions of $\mathrm{CO}, \mathrm{CO}_{2}$, and $\mathrm{NO}_{x}$}

In Figure 5, for all jet-to-jet spacing, the EICO increases with increasing Reynolds number but decreases with jet-to-plate distance. For the constant Reynolds number and jet-to-plate distance, the EICO decreases when the jet-to-jet spacing was increased from 1 to 2.5. With a further increase in the jet-to-jet spacing to 4, the EICO slightly increases. Moreover, the percentage of variation is higher with a lower Reynolds number and higher jet-to-plate distance.

The variation of $\mathrm{CO}$ emission can be codetermined by its production process and oxidization process. The production of $\mathrm{CO}$ from the fuel can affect the $\mathrm{CO}$ concentration in the flame directly, while $\mathrm{CO}$ oxidization can be influenced by the oxidizer concentration in the premixed gases, the ambient air entrainment, and the gases temperature [11]. As the $H$ /de ratio increases, more ambient air can be entrained to the flame so as to accelerate the $\mathrm{CO}$ oxidization, resulting in a reduction of the $\mathrm{CO}$ emission, as shown in Figure 5. In addition, at a larger Reynolds number, the flame spreads along the surface of the target plate owing to the increased flame height. This results in more chemical reactions being inhibited by the cold target plate and the burned gases being cooled down effectively [21], leading to the high $\mathrm{CO}$ emission at larger Re with the same H/de, as shown in Figure 5. 


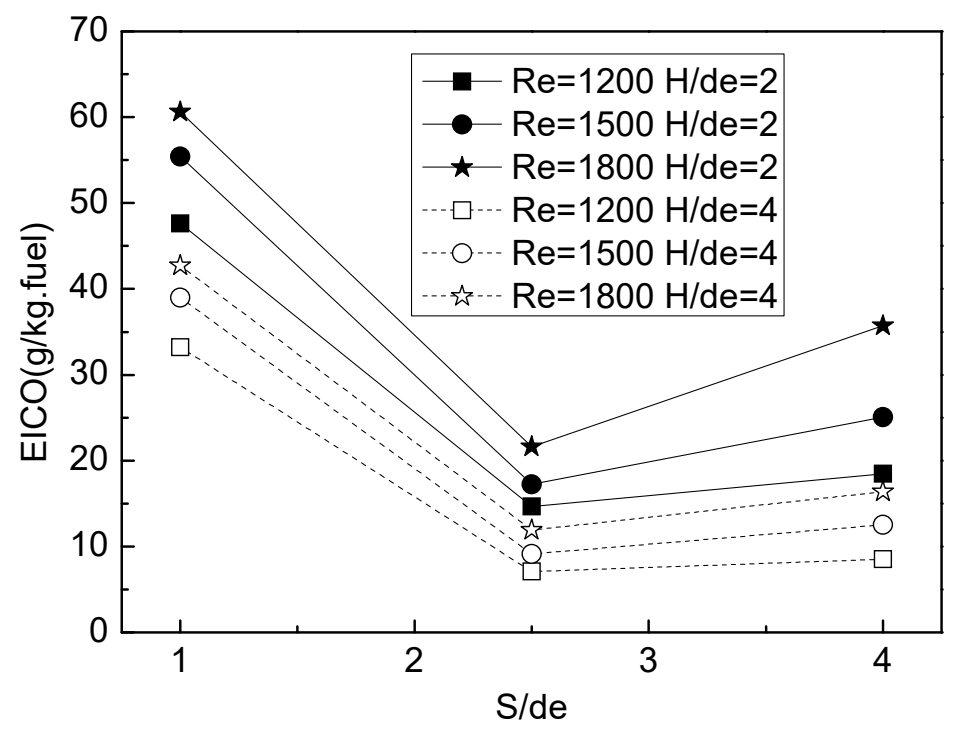

Figure 5. EICO of slot LPG premixed flame array at different conditions.

At the $S$ / de ratio of 1 , the ambient air entrainment can be suppressed considerably due to the quite strong jet interaction, while the outward burned gases suffer the significantly strong cooling effects of the cold plate. This can decelerate the CO oxidization efficiently by the combined effects of an insufficient oxidizer and decreased temperature. As the $S /$ de ratio is increased to 2.5 , the jet interaction can be weakened effectively, which makes for the longer residence time and more air entrainment to improve the $\mathrm{CO}$ oxidization process more efficiently than that at $S / d e=1$, as shown in Figure 5. With the further increased jet-to-jet spacing $(S / d e=4)$, the intensive entrainment of ambient air leads to the dilution effect beginning to play the dominant role in the $\mathrm{CO}$ emission. Specifically, the larger jet-tojet spacing brings about the more intensive air entrainment and the longer residence time for the $\mathrm{CO}$ oxidization. Although the considerably increased air entrainment can still make for $\mathrm{CO}$ oxidization by providing more available oxidizer, the much lower temperature of ambient air can decrease the burned gases temperature considerably and suppress the $\mathrm{CO}$ oxidization significantly [24]. As a result, it is known that the negative effect of more air entrainment overcomes its positive effect on the $\mathrm{CO}$ oxidization, giving rise to the worse $\mathrm{CO}$ oxidization process and the higher $\mathrm{CO}$ emission at $S / d e=4$ than that at $S / d e=2.5$, as shown in Figure 5.

The $\mathrm{EICO}_{2}$ shows the opposite variation trend with the EICO, as shown in Figure 6. The $\mathrm{EICO}_{2}$ increases with decreasing Reynolds number and jet-to-plate distance. Moreover, for the constant Reynolds number and jet-to-plate distance, the $\mathrm{EICO}_{2}$ increases when the jet-to-jet spacing is increased from 1 to 2.5 . With the further increased jet-to-jet spacing $(S / d e=4)$, the $\mathrm{EICO}_{2}$ decreases slightly with the jet-to-plate distance of 2 and 4 . The $\mathrm{EICO}_{2}$ and EICO are related to the fuel combustion efficiency. The higher EICO indicates lower combustion efficiency generally and thus results in the lower $\mathrm{EICO}_{2}$. Hence, the reason leading to the variation of EICO emission can also be adopted to explain how $\mathrm{EICO}_{2}$ emission is affected by different operation conditions.

Figure 7 shows the variation of the EINO ${ }_{x}$ of the LPG flame array at different conditions. It is seen that the $\mathrm{EINO}_{\mathrm{x}}$ increases with the increased jet-to-plate distance but decreases with the increasing Reynolds number. It is known that $\mathrm{NO}_{x}$ formation depends on the oxygen concentration, the flame temperature, and the gas residence time simultaneously. The higher jet-to-plate distance or smaller $R e$ leads to the higher oxygen concentration in the reaction region, owing to the more intensive air entrainment and thus higher $\mathrm{NO}_{\mathrm{x}}$ emission. In addition, the high-temperature post-flame region extends over a longer distance and allows the increased residence time to form thermal $\mathrm{NO}_{\mathrm{x}}$ [25]. Similar results were found by Saha et al. [21] with premixed impinging rich methane jet flames. In addition, for the same Reynolds number and jet-to-plate distance, the $\mathrm{EINO}_{\mathrm{x}}$ has the 
lowest value at the jet-to-jet spacing of 1 . As the $\mathrm{S} /$ de ratio is increased, the $\mathrm{EINO}_{\mathrm{x}}$ can be increased significantly. This is because the increased jet-to-jet spacing can make for more effective ambient air entrainment in the burned gases of the flame array and then accelerate the NOx formation significantly in the post-flame region.

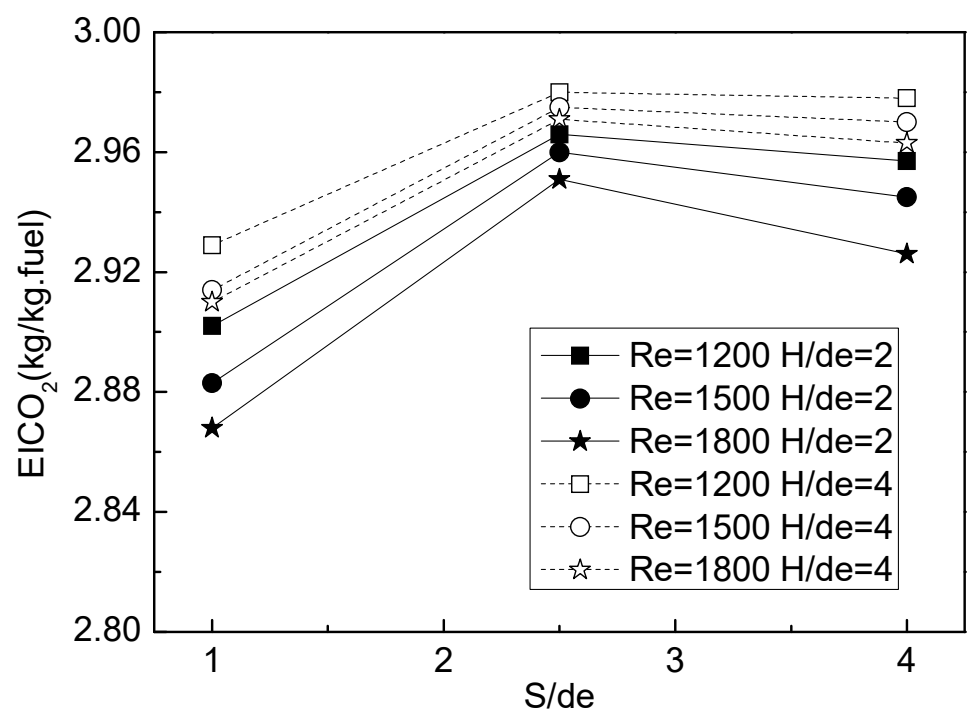

Figure 6. $\mathrm{EICO}_{2}$ of slot LPG premixed flame array at different conditions.

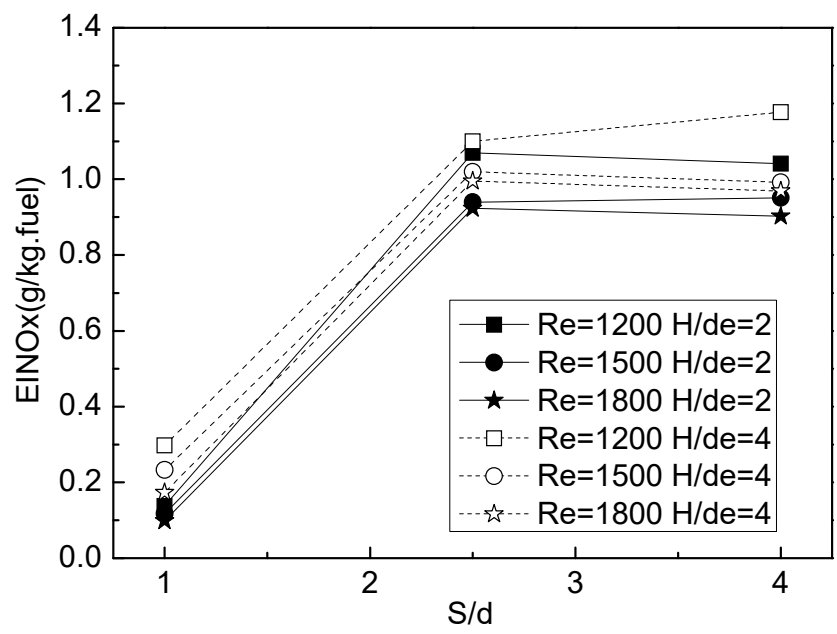

Figure 7. EINO $\mathrm{E}_{\mathrm{x}}$ of slot LPG premixed flame array at different conditions.

The $\mathrm{EINO}_{2}$ variations of flame array at different conditions are compared in Figure 8. At the smallest jet-to-jet spacing of 1 , the $\mathrm{EINO}_{2}$ is quite small, and there is no significant difference for different Reynolds number and jet-to-plate distance. At a higher jet-to-jet spacing 2.5 and 4, the $\mathrm{EINO}_{2}$ decreases with the increase in Reynolds number but increases with a larger jet-to-plate distance. Furthermore, compared with that at the jet-to-jet spacing of 2.5, $\mathrm{EINO}_{2}$ has the slightly higher value at the jet-to-jet spacing of 4 . This can be explained as follows. The lower Reynolds number, larger jet-to-jet spacing, and increased jet-to-plate distance can lead to more available oxygen in the combustion region and then contribute to the higher $\mathrm{EINO}_{2}$ emission [11].

\subsection{Comparison of the Heat Transfer and Emission Characteristic of Slot and Circular Jet Flames}

Both slot and circular Jet flames have been used in the heating industry. To better understand the individual characteristics of these two jet flames, the heat transfer performance and exhaust gas emission characteristics of an array of impinging slot and circular 
flame jets are compared in this part, and the average heat flux and exhaust emission index are chosen under the condition of $R e=1500$ for $H / d e=2$ and $4, S / d e=1,2.5$ and 4 .

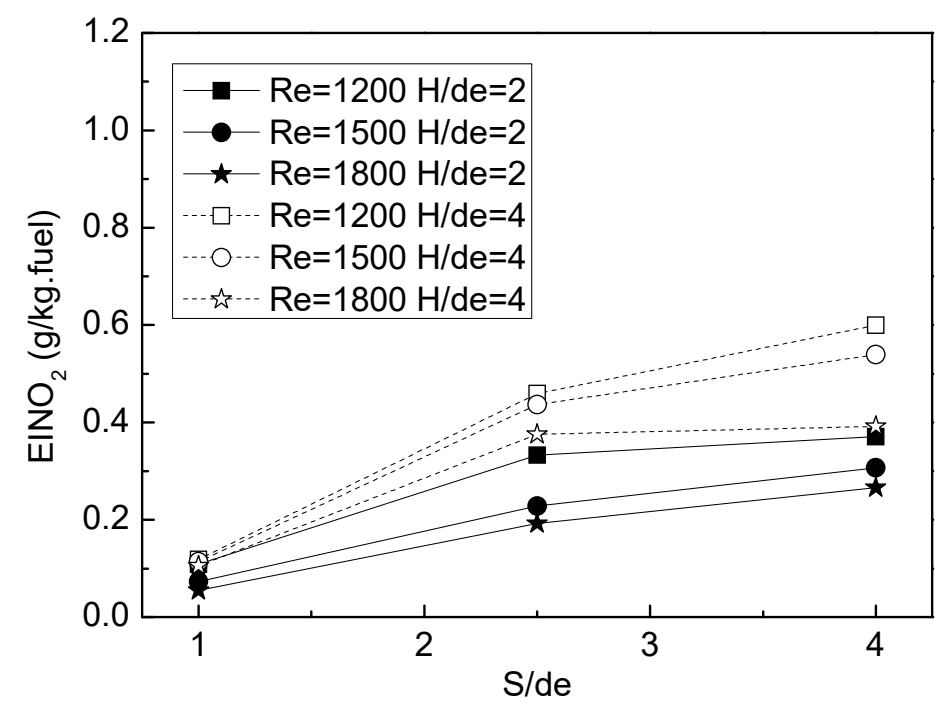

Figure 8. $\mathrm{EINO}_{2}$ of slot LPG premixed flame array at different conditions.

\subsubsection{Comparison of the Average Heat Flux}

Figure 9 shows the average heat fluxes for a slot flame jet and circular flame jet. It is seen that average heat fluxes decrease at a higher jet-to-plate distance, and the maximum value can be obtained at the jet-to-jet of 2.5. For all the tested conditions, the slot flame jets have better heat transfer performance than that of circular jets.

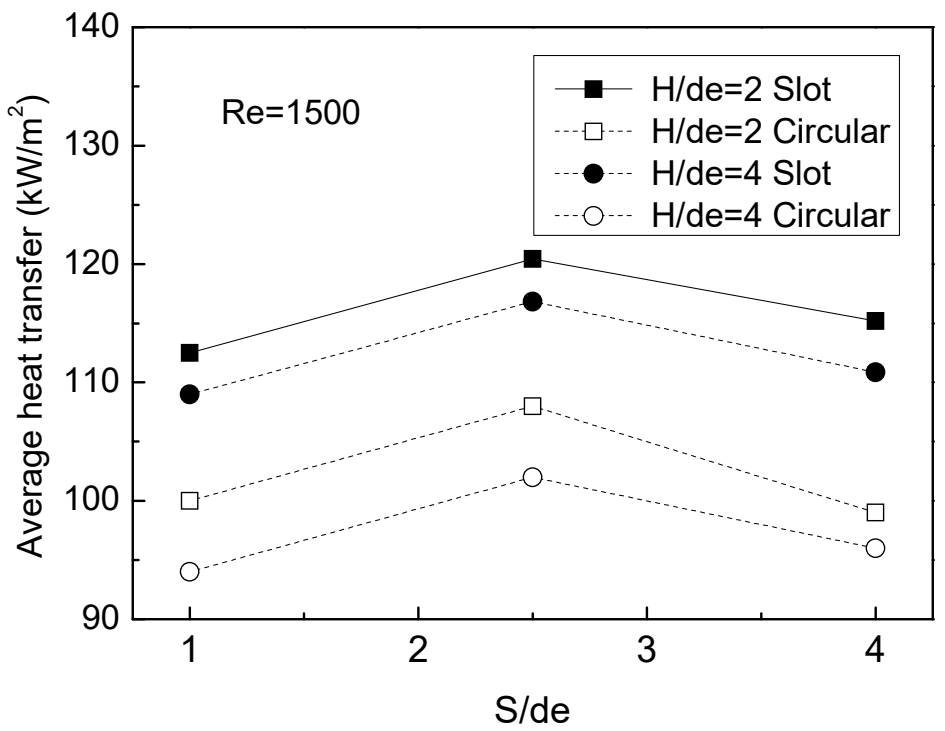

Figure 9. Comparison of area-averaged heat flux of slot and round LPG flame array at $R e=1500$.

For the single jet, according to the studies of Kwok et al. [6], the circular jet has a higher peak flux located at the impinging region compared with that of the slot jet. The rapid decrease in the heat flux of the circular jet contributes the small contact area for impingement heat transfer. By contrast, the slot jet can provide the more uniform heat flux distributions in the horizontal plate in both the $x$ and $y$ directions. This gives rise to the heat flux of the slot flame jet having a much more moderately decreasing slope than that of the circular flame jet, which results in a larger surface area with higher average heat flux. Hence, the area-averaged heat transfer of the slot jet is much higher than that of the circular 
jet. For the multiple jets, besides the above reason, it is proposed that the effect of jet-to-jet spacing can be more significant on the circular flame jets than the slot jets. Compared with the slot flame jets, a greater discrepancy of average heat flux between the central and side jets can be observed in the case of the circular jets [1]. Overall, it is known that the multiple slot flame jets can be suggested to be more capable of generating higher and more uniform heat flux along the impingement plate.

\subsubsection{Comparison of the Emission Characteristics}

Figure 10a,b show the comparison of the EICO and $\mathrm{EINO}_{\mathrm{x}}$ for the slot and circular jets. There are similar EICO variations for the slot and circular jets. Specifically, the EICO decreases with the jet-to-plate distance, and the maximum EICO occurs at the jet-to-plate distance of 1 . However, compared with the slot jets, the value of EICO is about $30-50 \%$ lower than that of the circular jets. At the same Reynolds number, the mass of the fuel/air mixture supplied in the slot and circular flame jets is the same. In the slot pattern setting, since the jet interaction occurs between the length sides of the center and side jets, the air entrainment in the jet interaction zone can be suppressed considerably. This contributes to the much higher $\mathrm{CO}$ emission of the slot jet pattern than that of the circular jet pattern, as shown in Figure 10a.

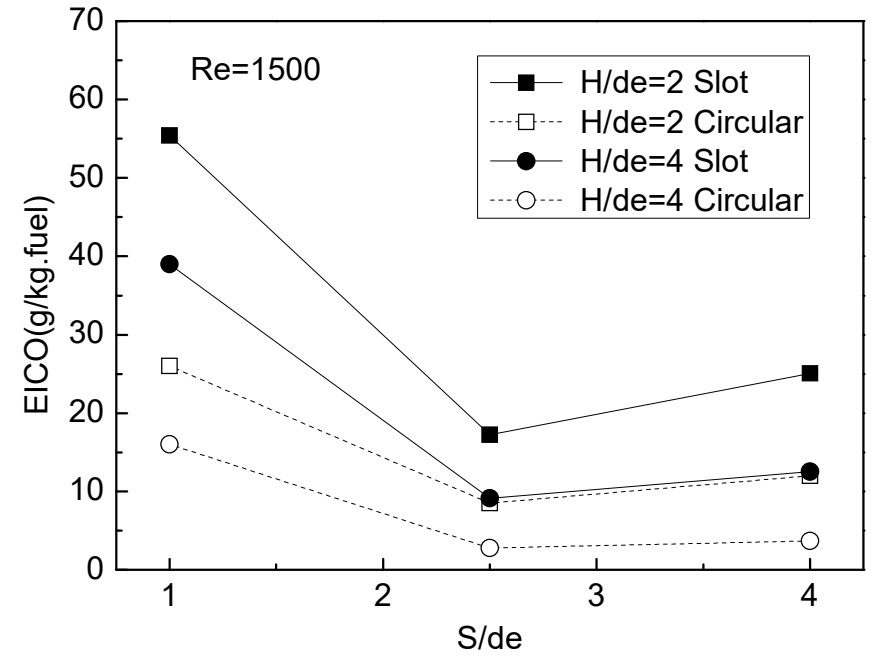

(a)

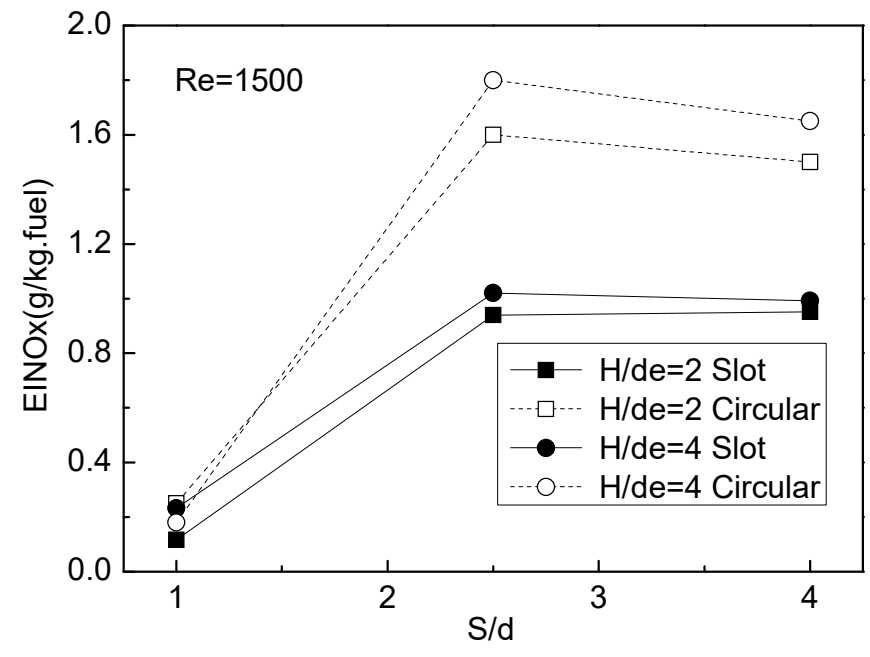

(b)

Figure 10. Comparison of EICO (a) and $\mathrm{EINO}_{\mathbf{x}}(\mathbf{b})$ of slot and round LPG flame array at $\operatorname{Re}=1500$.

As shown in Figure 10b, at the jet-to-jet spacing of 1, the EINO ${ }_{x}$ values for both slot jets and circular jets are quite low with the $\mathrm{EINO}_{\mathrm{x}}$ being slightly higher for the circular jets. At the other two jet-to-jet spacings, compared with slot jets, the $\mathrm{EINO}_{\mathrm{x}}$ increases evidently by $58-76 \%$ for the circular jets. In addition, it is noted that at larger jet-to-jet spacing, more oxygen is available in the combustion region and results in higher EINO $_{x}$ for both the slot jets and circular jets. The much higher EINOx of circular jets can result from the more effective air entrainment for the circular flame pattern, which provides more available oxidizer for the NOx production.

\section{Conclusions}

Experiments were conducted to investigate the effect of Reynolds number, jet-to-jet spacing, and jet-to-plate distance on the heat transfer and exhaust emissions of an array of three premixed LPG/air slot flame jets impinging upwards normally on a horizontal water-cooled flat plate. In addition, the thermal and emission characteristics of slot jets and circular jets were compared and discussed under the same experimental conditions. The following conclusions can be drawn from this study. 
1. The local heat flux can be codetermined by the jet interaction, cool core of the flame, and the Reynolds number. The strong jet interaction can result in the lower local heat flux due to the worse field synergy, while the cool core can make sense at a larger jet-to-jet spacing to reduce the local heat flux at the flame axis. In addition, although the larger Reynolds number can make the jet interaction more intensive, it can improve the convective heat transfer more effectively and results in the increased local heat flux. The more uniform heat flux distribution and higher total heat flux can be obtained at the moderate jet-to-jet spacing, large jet-to-plate distance, and higher Reynolds number.

2. EICO emission is influenced by the combined effects of jet-to-jet spacing, jet-to-plate distance, and higher Reynolds number. Small jet-to-jet spacing, a lower jet-to-plate distance, and a higher Reynolds number can provide insufficient oxygen in the burned gases of the flame array due to the relatively worse ambient air entrainment, which results in the higher EICO and lower $\mathrm{EICO}_{2}$. To obtain the better combustion efficiency and lower EICO emission, the moderate jet-to-jet spacing, larger jet-to-plate distance, and relatively higher Reynolds number are suggested for the slot jet flame array. In addition, the $\mathrm{EINO}_{\mathrm{x}}$ emission increases with the increased jet-to-plate distance and the lower Reynolds number due to the more available oxidizer and longer residence time. Thus, it is found that there exists a trade-off between the EICO and EINOx.

3. Compared with multiple circular flame jets, multiple slot flames jets have the higher area-averaged heat flux due to the larger heating area and more uniform heat flux

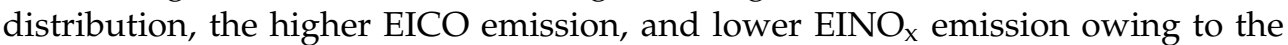
greater jet interaction suppressing the air entrainment. Hence, it is known that the slot flame array can have better heating performance but higher pollutant emissions than the circular flame array.

Author Contributions: Conceptualization, H.Z. and X.L.; methodology, Z.W.; validation, B.D., H.Z. and Z.W.; resources, Z.L. All authors have read and agreed to the published version of the manuscript.

Funding: Hainan Provincial Natural Science Foundation of China (520RC534, 520QN227, 519MS023). Institutional Review Board Statement: Not applicable.

Acknowledgments: The authors thank Hainan Provincial Natural Science Foundation of China (520RC534, 520QN227, 519MS023) for financial support of the present study.

Conflicts of Interest: The authors declare no conflict of interest.

\section{References}

1. Dong, L.; Leung, C.; Cheung, C.S. Heat transfer of a row of three butane/air flame jets impinging on a flat plate. Int. J. Heat Mass Transf. 2003, 46, 113-125. [CrossRef]

2. Dong, L.L.; Leung, C.W.; Cheung, C.S. Heat transfer characteristics of a pair of impinging rectangular flame jets. J. Heat Transf. 2003, 125, 1140-1146. [CrossRef]

3. Zhen, H.; Zhang, L.; Wei, Z.; Chen, Z.; Huang, Z. A numerical study of the heat transfer of an impinging round-jet methane Bunsen flame. Fuel 2019, 251, 730-738. [CrossRef]

4. Wei, Z.; Zhen, H.; Leung, C.; Cheung, C.; Huang, Z. Heat transfer characteristics and the optimized heating distance of laminar premixed biogas-hydrogen Bunsen flame impinging on a flat surface. Int. J. Hydrogen Energy 2015, 40, 15723-15731. [CrossRef]

5. Wei, Z.; Leung, C.W.; Cheung, C.S.; Huang, Z. Effects of $\mathrm{H}_{2}$ and $\mathrm{CO}_{2}$ addition on the heat transfer characteristics of laminar premixed biogas-hydrogen Bunsen flame. Int. J. Heat Mass Transf. 2016, 98, 359-366. [CrossRef]

6. Kwok, L.; Leung, C.; Cheung, C. Heat transfer characteristics of an array of impinging pre-mixed slot flame jets. Int. J. Heat Mass Transf. 2005, 48, 1727-1738. [CrossRef]

7. Chander, S.; Ray, A. Heat transfer characteristics of three interacting methane/air flame jets impinging on a flat surface. Int. J. Heat Mass Transf. 2007, 50, 640-653. [CrossRef]

8. Mohr, J.W.; Seyed-Yagoobi, J.; Page, R.H. Heat transfer from a pair of radial jet reattachment flames. J. Heat Transf. 1997, 119, 633-635. [CrossRef]

9. $\mathrm{Wu}, \mathrm{J} . ;$ Seyed-Yagoobi, J.; Page, R. Heat transfer and combustion characteristics of an array of radial jet reattachment flames. Combust. Flame 2001, 125, 955-964. [CrossRef] 
10. Zhen, H.S.; Wei, Z.L.; Leung, C.W.; Cheung, C.S.; Huang, Z.H. Emission of impinging biogas/air premixed flame with hydrogen enrichment. Int J Hydrogen Energy 2016, 41, 2087-2095. [CrossRef]

11. Wei, Z.; Zhen, H.; Leung, C.; Cheung, C.; Huang, Z. Experimental and numerical study on the emission characteristics of laminar premixed biogas-hydrogen impinging flame. Fuel 2017, 195, 1-11. [CrossRef]

12. Mishra, D. Emission studies of impinging premixed flames. Fuel 2004, 83, 1743-1748. [CrossRef]

13. Mohr, J.; Seyed-Yagoobi, J.; Page, R. Combustion measurements from an impinging radial jet reattachment flame. Combust. Flame 1996, 106, 69-80. [CrossRef]

14. Li, H.; Zhen, H.; Leung, C.; Cheung, C.S. Effects of plate temperature on heat transfer and emissions of impinging flames. Int. J. Heat Mass Transf. 2010, 53, 4176-4184. [CrossRef]

15. Wei, Z.; Zhen, H.; Leung, C.; Cheung, C.; Huang, Z. Effects of $\mathrm{H}_{2}$ addition on the formation and emissions of $\mathrm{CO} / \mathrm{NO} / \mathrm{NOx}$ in the laminar premixed biogas-hydrogen flame undergoing the flame-wall interaction. Fuel 2020, 259, 116257. [CrossRef]

16. Wei, Z.; Zhen, H.; Leung, C.; Cheung, C.; Huang, Z. Effects of unburned gases velocity on the $\mathrm{CO} / \mathrm{NO}_{2} / \mathrm{NO}_{\mathrm{x}}$ formations and overall emissions of laminar premixed biogas-hydrogen impinging flame. Energy 2020, 196, 117146. [CrossRef]

17. Pérez, S.; Del Molino, E.; Barrio, V.L. Modeling and Testing of a milli-structured reactor for carbon dioxide methanation. Int. J. Chem. React. Eng. 2019, 17. [CrossRef]

18. Yin, C.; Qiu, S.; Zhang, S.; Sher, F.; Zhang, H.; Xu, J.; Wen, L. Strength degradation mechanism of iron coke prepared by mixed coal and Fe2O3. J. Anal. Appl. Pyrolysis 2020, 150, 104897. [CrossRef]

19. Qureshi, Y.; Ali, U.; Sher, F. Part load operation of natural gas fired power plant with $\mathrm{CO}_{2}$ capture system for selective exhaust gas recirculation. Appl. Therm. Eng. 2021, 190, 116808. [CrossRef]

20. Kline, S.J.; McClintock, F. Describing uncertainties in single-sample experiments. Mech. Eng. 1953, 75, 3-8.

21. Saha, C.; Ganguly, R.; Datta, A. Heat transfer and emission characteristics of impinging rich methane and ethylene jet flames. Exp. Heat Transf. 2008, 21, 169-187. [CrossRef]

22. Dong, L.; Cheung, C.; Leung, C. Heat transfer from an impinging premixed butane/air slot flame jet. Int. J. Heat Mass Transf. 2002, 45, 979-992. [CrossRef]

23. Zhen, H.; Leung, C.W.; Cheung, C.S. A comparison of the heat transfer behaviors of biogas- $\mathrm{H}_{2}$ diffusion and premixed flames. Int. J. Hydrogen Energy 2014, 39, 1137-1144. [CrossRef]

24. Wei, Z.; Zhen, H.; Leung, C.; Cheung, C.; Huang, Z. Formations and emissions of $\mathrm{CO} / \mathrm{NO}_{2} / \mathrm{NOx}$ in the laminar premixed biogas-hydrogen flame undergoing the flame-wall interaction: Effects of the variable $\mathrm{CO}_{2}$ proportion. Fuel 2020, $276,118096$. [CrossRef]

25. Hou, S.-S.; Ko, Y.-C. Effects of heating height on flame appearance, temperature field and efficiency of an impinging laminar jet flame used in domestic gas stoves. Energy Convers. Manag. 2004, 45, 1583-1595. [CrossRef] 